\title{
ON THE USE OF SENTINEL-2 IMAGES AND HIGH RESOLUTION DTM FOR LANDSLIDE SUSCEPTIBILITY MAPPING IN A DEVELOPING URBAN SETTLEMENT (MAMAK, ANKARA, TURKEY)
}

\author{
T. $\operatorname{Yanar}^{1}$, S. Kocaman ${ }^{1, *}$, C. Gokceoglu ${ }^{2}$ \\ ${ }^{1}$ Dept. of Geomatics Engineering, Hacettepe University, 06800 Beytepe Ankara, Turkey - (yanar.tugce@ gmail.com; \\ sultankocaman@hacettepe.edu.tr) \\ ${ }^{2}$ Dept. of Geological Engineering, Hacettepe University, 06800 Beytepe Ankara, Turkey - (cgokce@ hacettepe.edu.tr)
}

GI4DM 2019

KEY WORDS: Developing Urban Settlements, Sentinel-2, DTM, Landslide Susceptibility Mapping, Logistic Regression

\begin{abstract}
:
Urban planning starts with the selection of suitable sites. The main factors and components for site selection are the geologicalgeotechnical parameters that directly affect the natural hazards, such as landslide and flood, construction costs and the location and distribution of existing infrastructure. The presence and accuracy of up-to-date maps in planning are very important. With the increase of high resolution Earth observation satellites, the required data can be obtained with high temporal frequency and spatial availability. From these data, the base parameters for planning can be extracted with semi- or fully-automatic methods. Among the Earth observation satellites, the Sentinel-2 mission of European Space Agency (ESA) provides high resolution optical images and the data are freely available also at different processing levels such as orthorectified images.

In this study, the possibility of the landslide susceptibility map production which should be one of the base maps in urban planning by using Sentinel-2 satellite images was investigated in Mamak District of Ankara City, Turkey. The land cover and land use data were produced from Sentinel-2 images by using a supervised classification method in SNAP Tool provided by ESA. The lithological definitions were received from the General Directorate of Mineral Research and Explorations. The topographical parameters such as slope, aspect, topographic wetness index, etc. were extracted from a high resolution digital terrain model (DTM) of the area. Manually extracted landslide inventory data were employed in the logistic regression method and the produced landslide susceptibility map of the study area is presented here.
\end{abstract}

\section{INTRODUCTION}

Natural disasters are events that cause loss of lives and properties. Due to the rapid growth of population and inadequate land use planning, harmful effects of natural disasters are increasing in rural and urban areas of developing countries. In addition, the role of existing infrastructure and human impact are in general neglected in urban planning frameworks (Mulero et al., 2018). A combined approach for land use planning that take infrastructure, human effect, and natural hazard potential is needed and recent developments in geoformation tools and technologies for data collection and analysis can provide the required means for this purpose.

Landslide is one of the most common natural hazard which occurs all over the world. Disasters caused by landslides damage buildings, infrastructure and other public facilities in the settlement areas. Between 1950 and 2018, a total of 23.041 landslides were recorded in Turkey (AFAD, 2019). The determination of landslide prone areas plays an important role in urban planning and disaster mitigation actions organized by local governments. Thematic maps on landslide susceptibility, hazard and disaster risks can demonstrate their spatial characteristics and the potential environmental and societal effects.
For the production of landslide susceptibility maps, geomorphological (e.g. topographical, hydrological, etc.), geological (e.g. lithology) and land use and land cover (LULC) features of the area of interest should be taken into account. The geomorphological characteristics should be derived from a high resolution digital terrain model (DTM) to obtain the required level of detail in an urban area. Although the geological and geomorphological characteristics may not deviate much in a short time span, the LULC changes very quickly especially in a developing urban settlement. Due to the importance of LULC data in landslide susceptibility mapping (Chen et al., 2019), up-to-date data that represent the most recent LULC pattern are needed to obtain high accuracy. In addition, existing landslide inventories are required for this purpose. However, preparation of landslide inventory in urban settlements and heavy construction sites is very difficult since the topography is either covered or largely modified that obstruct the visibility of landslides considerably.

The main aim of this study is to investigate the usability of Sentinel-2 images for producing timely accurate landslide susceptibility map for a part of Mamak District in Ankara, Turkey together with high resolution DTM and lithology data obtained from national geodatabases. Satellite optical images are obtained regularly over a large geographical extent and European Space Agency (ESA) provide geometrically corrected (i.e. orthorectified, L2B) Sentinel-2 images

\footnotetext{
* Corresponding author
} 
regularly. The Sentinel-2 satellite is a multi-band (13 bands in total) Earth observation satellite launched by the ESA (2019), with ground sampling distances (GSD) of $10 \mathrm{~m}, 20 \mathrm{~m}$ and 60 $\mathrm{m}$, and a high transmission frequency (Sentinel-2 coverage map, 2019). The spatial resolution of the multispectral channel images $(10 \mathrm{~m})$ is sufficient for the purposes of this study. In addition, the SNAP Tool provided by ESA is easy to use and free, which satisfies the needs of urban planners who may not be remote sensing experts. The frequency of repetition through the same orbit is 5 days and the frequency of repeating the same site is higher due to overlapping trajectories. The images of Sentinel-2 are widely used in natural hazard analysis (Poursanidis and Chrysoulakis, 2017).

Although a massive amount of landslide susceptibility mapping studies and methods exist in the literature (e.g. Nefeslioglu et al., 2008; Pham et al., 2018; Gorum et al., 2008; Reichenbach et al., 2018, etc.), most studies were applied in rural areas and accurate production of such maps in urban settlement is difficult due to intense construction work and dense buildings. Logistic regression method is preferred here since it is simple and can take non-numerical parameters such as different LULC types into account. The output susceptibility map can be used as a base for urban planning practices by local governments.

\section{STUDY AREA}

Due to increased population, urban sprawl is a major issue for the urban development in Ankara, Turkey. Mamak District, located in the east of the city, is one of the development centre for this sprawl. There are also known landslide risks in the area where 637.935 people live. Mamak is also a main gate of Ankara connecting the city to the Eastern Turkey with major transportation infrastructure (e.g. highways, railways). In addition, Bayindir dam is located here. A part of Mamak District (Figure 1) with a geographic position extends from $39^{\circ} 53^{\prime} 41.689^{\prime \prime} \mathrm{N}$ to $39^{\circ} 56^{\prime} 27.108^{\prime \prime} \mathrm{N}$ latitude and $32^{\circ} 56^{\prime} 51.372^{\prime \prime} \mathrm{E}$ to $33^{\circ} 0^{\prime} 57.578^{\prime \prime} \mathrm{E}$ longitude was considered as the study area. The coverage of the study area is $30 \mathrm{~km}^{2}$ and the altitude ranges from $924 \mathrm{~m}$ to $1284 \mathrm{~m}$. Existing construction and urban expansion potential were taken into consideration for the selection.

\section{METHODOLODY AND DATA}

Landslide susceptibility map of the study area was produced by employing LULC data obtained from the classified Sentinel-2 images, topographical characteristics derived from high-resolution DTM, and the lithological parameters in a logistic regression process. By analyzing the output map, the landslide occurrence potential of the study area was interpreted by engineering geologists and urban planners to propose appropriate planning principles. The main workflow of the study is given in Figure 2.

\subsection{Input Datasets}

A high resolution grid DTM of the region with $5 \mathrm{~m}$ intervals and vector data (breaklines) representing the geomorphological characteristics were produced by General Directorate of Mapping from aerial photogrammetric flight missions, and provided for the study area. Topographical parameters such as altitude, slope, general curvature, plan and profile curvatures, topographic wetness index (TWI), stream power index (SPI), distance to channel networks and ridgelines are derived from the grid DTM and the breaklines.

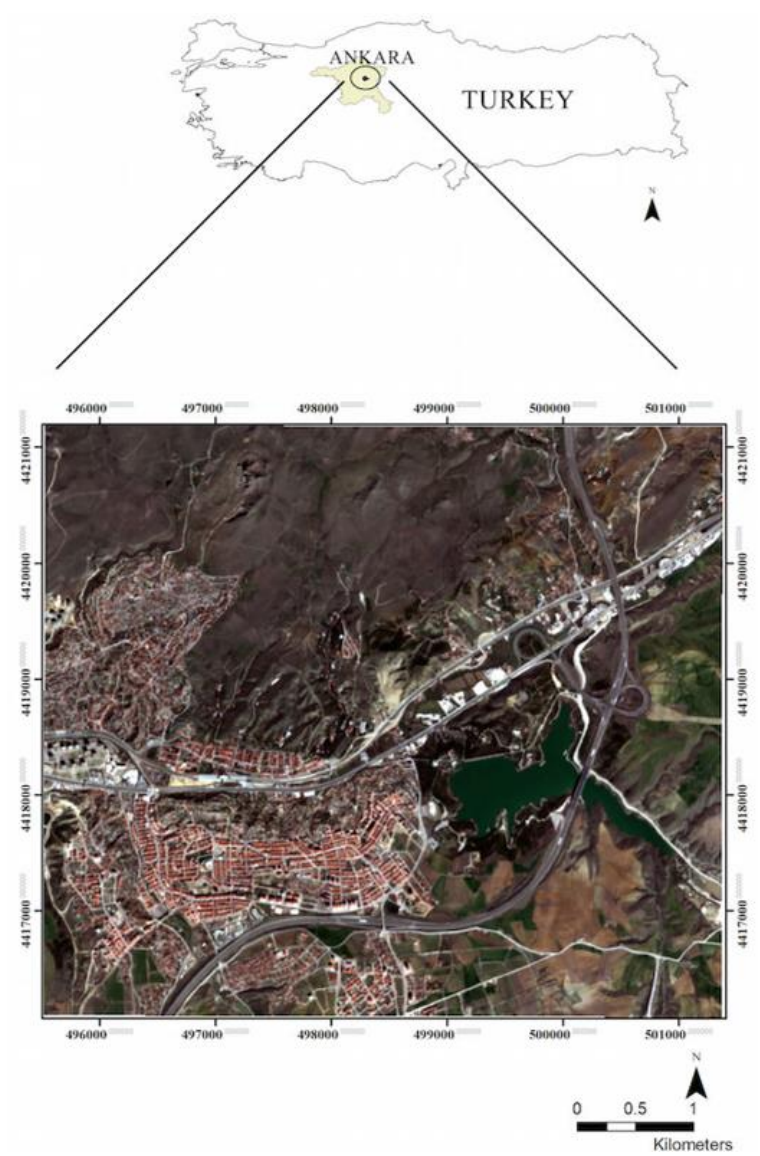

Figure 1. The location of the study area and an overview of the Sentinel-2 RGB image used in the study

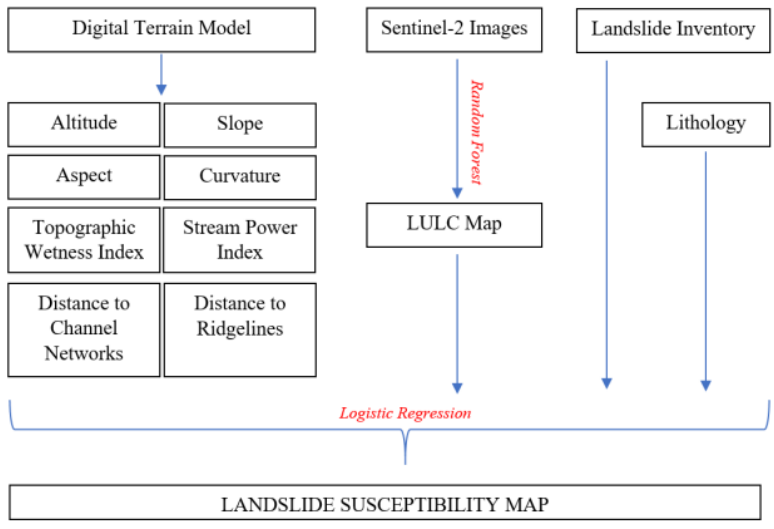

Figure 2. Overall workflow of the study

The Sentinel-2 satellite images were acquired on March $23^{\text {rd }}$, 2019, and used for generating LULC maps with a supervised classification technique (i.e. Random Forest). The lithological characteristics of the region were obtained from the Yer Bilimleri Portali provided by the General Directorate of Mineral Research and Exploration (Akbas et al., 2002). All data were rasterized with the same grid interval $(5 \mathrm{~m})$ to apply the logistic regression method. Eight landslides were manually delineated by the expert to calculate the logistic regression coefficients (Figure 3). 


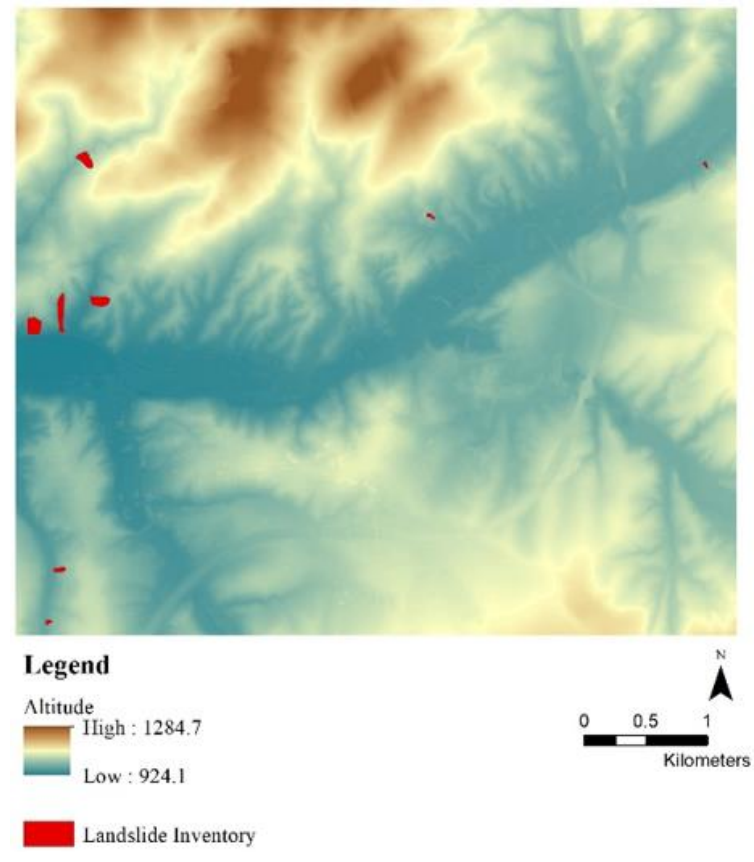

Figure 3. The altitude ranges and the landslide inventory in the study area.

\subsection{Topographic Attributes}

Areas are defined with some environmental scalars for understanding topography. These scalars include primary and secondary topographic attributes, which are calculated with taking derivatives of DTM. Primary topographic attributes such as slope, aspect, curvature etc. are calculated from elevation data while secondary topographic behavior such as SPI and TWI are calculated from second derivatives of elevation data (Moore et al., 1991). In this study, these parameters were calculated using SAGA GIS (2019) and ArcGIS (ESRI, 2019) software. Statistical attributes of the parameters are provided in Table 1.

\begin{tabular}{|l|r|r|r|r|}
\hline & \multicolumn{1}{|c|}{ Min } & \multicolumn{1}{c|}{ Max } & \multicolumn{1}{c|}{ Mean } & Std. Dev. \\
\hline Altitude (m) & 924.1 & 1284.7 & 1032.2 & 62.8 \\
\hline Slope (degree) & 0.004 & 73.127 & 13.075 & 8.719 \\
\hline $\begin{array}{l}\text { Aspect } \\
\text { (degree) }\end{array}$ & 0 & 360 & 192.23 & 101.46 \\
\hline $\begin{array}{l}\text { General } \\
\text { Curvature }\end{array}$ & -1.25957 & 1.09325 & $-9.73 \mathrm{E}-05$ & 0.05887 \\
\hline $\begin{array}{l}\text { Plan } \\
\text { Curvature }\end{array}$ & -0.09291 & 0.14917 & $4.56 \mathrm{E}-04$ & $9.69 \mathrm{E}-03$ \\
\hline $\begin{array}{l}\text { Profile } \\
\text { Curvature }\end{array}$ & -0.16431 & 0.16666 & $-5.05 \mathrm{E}-04$ & 0.01107 \\
\hline SPI & 0 & 3315271.5 & 688.02 & 14974.51 \\
\hline $\begin{array}{l}\text { TWI } \\
\text { Distance to } \\
\text { Channel (m) }\end{array}$ & 0.4 & 561.9 & 84.2 & 73.8 \\
\hline $\begin{array}{l}\text { Distance to } \\
\text { Ridgeline (m) }\end{array}$ & 0.0 & 229.9 & 33.0 & 26.5 \\
\hline
\end{tabular}

Table 1. Statistics of topographic attributes

Altitude is the measure of elevation in the area (Wilson, Gallant, 2000). The elevation ranges and the landslide inventory of the study area are shown in Figure 3. The slope gradient is expressed as a measure of the amount of change in height values (Wilson and Gallant, 2000) (Figure 4). It is used to understand the relationship between slope values and landslide formation.

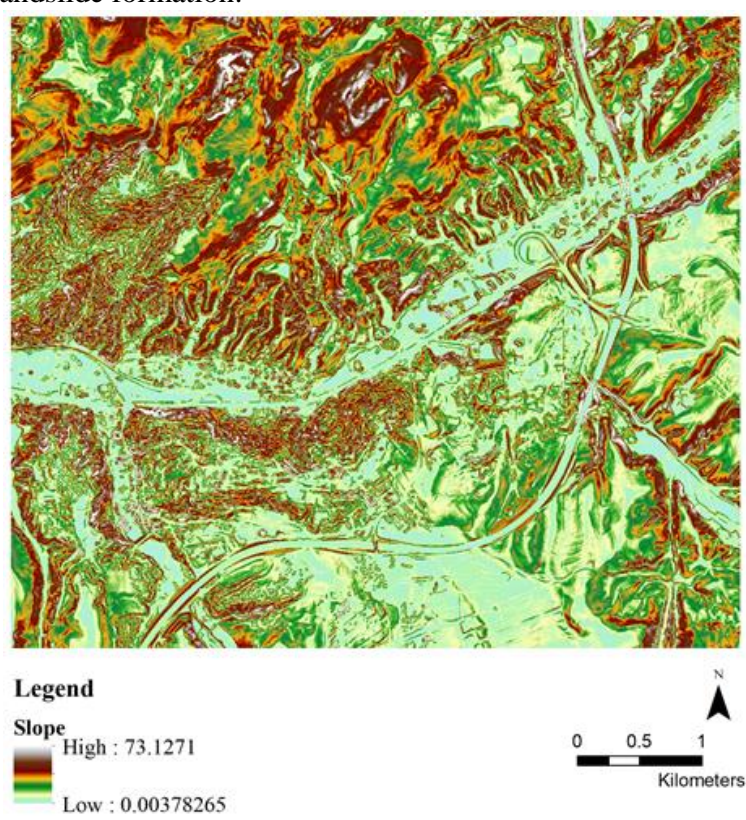

Figure 4. The slope gradient map of the study area

The slope direction is the direction of the steepest descent line and is usually measured in degrees clockwise starting from the north. The ratio of landslides is determined on which slopes (north, south, etc.) are higher than the others (Wilson and Gallant, 2000). The aspect values represent $90^{\circ}$ in North, $180^{\circ}$ in West, $270^{\circ}$ in South, and $360^{\circ}$ in East. The aspect map of the study area is shown in Figure 5.

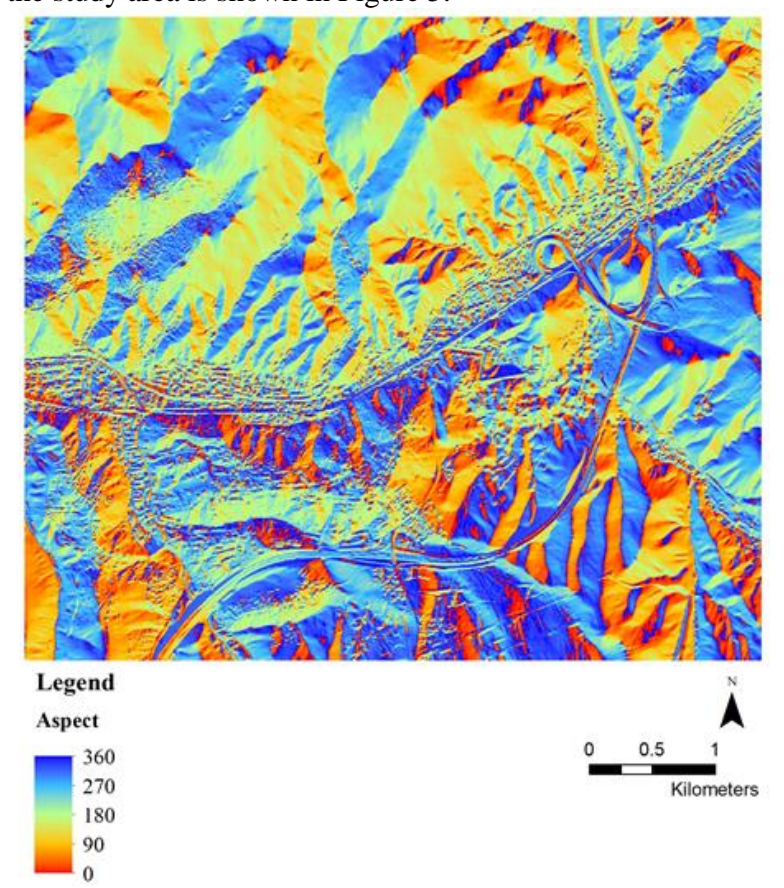

Figure 5. Aspect map of the study area

The rate of overall change of the first derivatives (slope gradient and slope direction) of digital elevation models (DEMs) represent the general curvature (Figure 6). The plan and profile curvatures are analyzed separately and corresponding maps are given in Figures 7 and 8. Plan curvature is the rate of change in the direction of slope along 
the contour lines and the profile curvature is the rate of change of the slope gradient in a slope (Wilson and Gallant, 2000). Curvatures can be negative that demonstrate that the surface is concave, or positive that demonstrate that the surface is convex or zero that the surface is flat (Budimir et al., 2014).

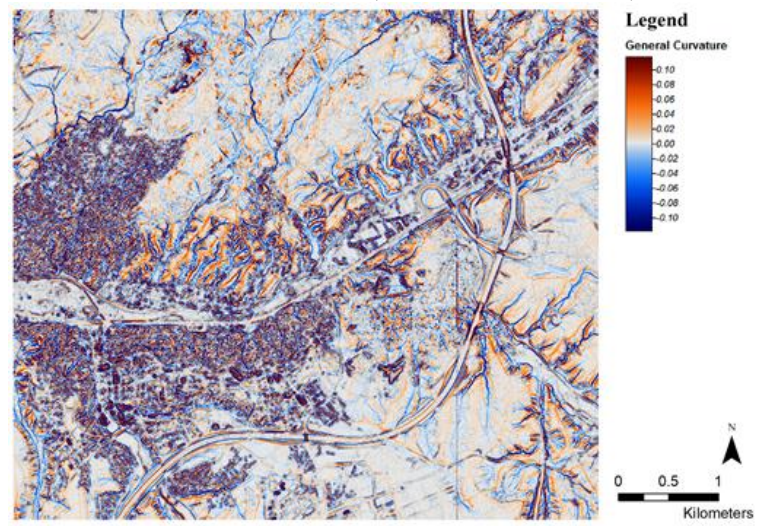

Figure 6. General curvature map of the study area.

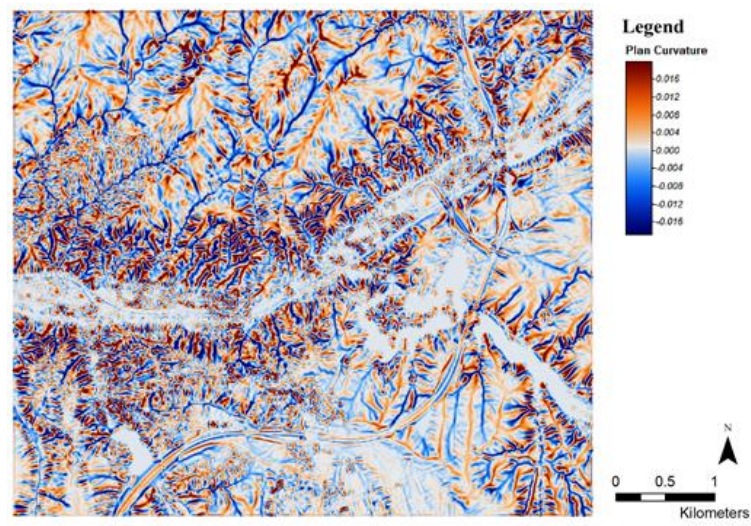

Figure 7. Plan curvature map of the study area.

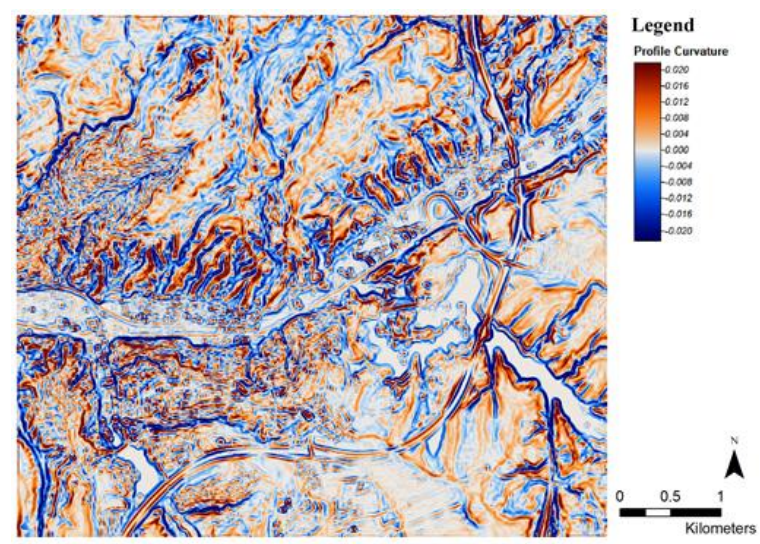

Figure 8 . Profile curvature map of the study area

The SPI indicates a measure of the abrasive power of flowing water (Zakerinejad and Maerker, 2015) (Figure 9). SPI is used for landslide susceptibility maps because of being denotive of the potential erosion energy of the sediments (Kakembo et al., 2009). The TWI is used in order to express the locations and dimensions of the water-saturated areas in the topographical sense (Moore et al., 1991) (Figure 10).
Vertical distances to channel networks are important for landslide susceptibility maps. With this topographic attribute, landslides which were occurred close to a channels are found. These channels are eliminated in the predicted landslide risks. Channel networks are derived from the DTM by calculating vertical distances to channel network (Samia et al., 2017). There is negative correlation between distance to ridgelines and landslide occurrence (Budimir et al., 2014). Ridgelines are derived by using flow direction and stream network created from DTM. The distance maps to channels and ridgelines are given in Figures 11 and 12.

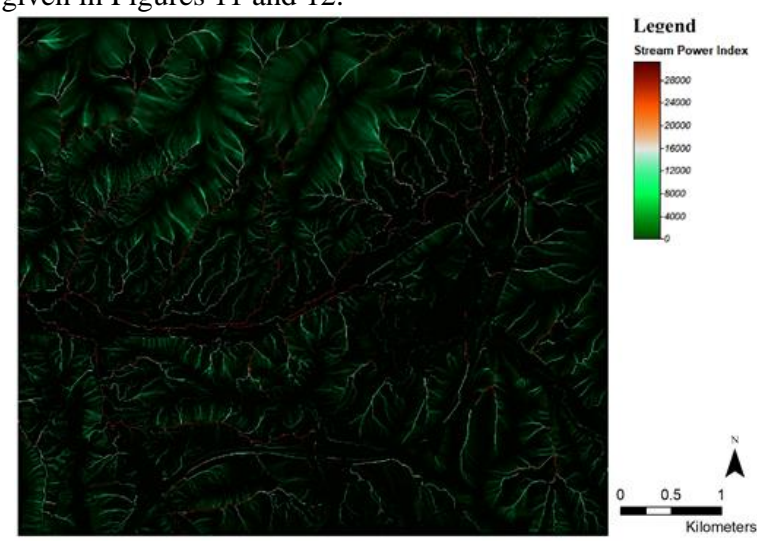

Figure 9. SPI map of the study area

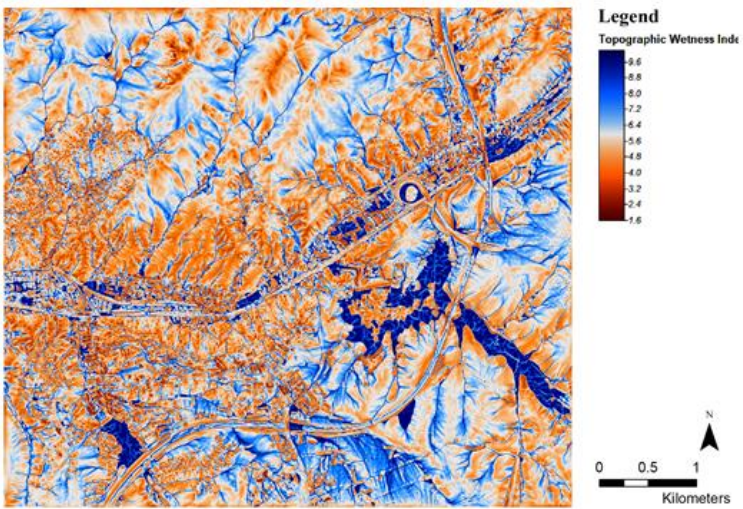

Figure 10. TWI map of the study area

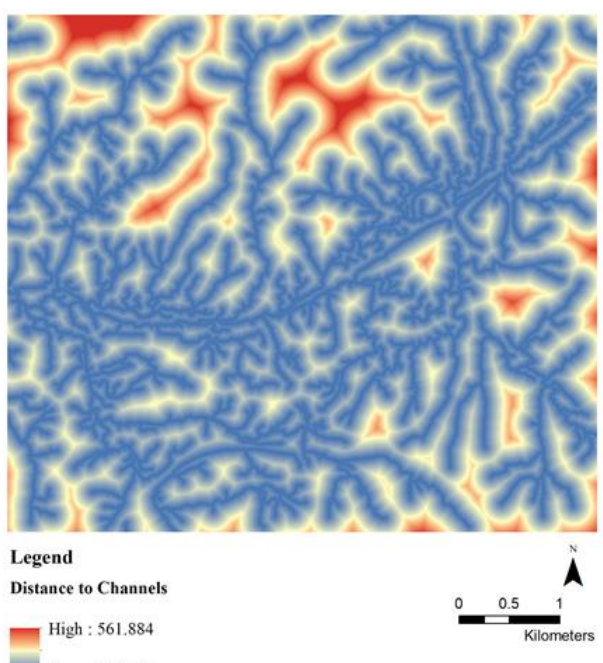

Figure 11. Distances to channels. 


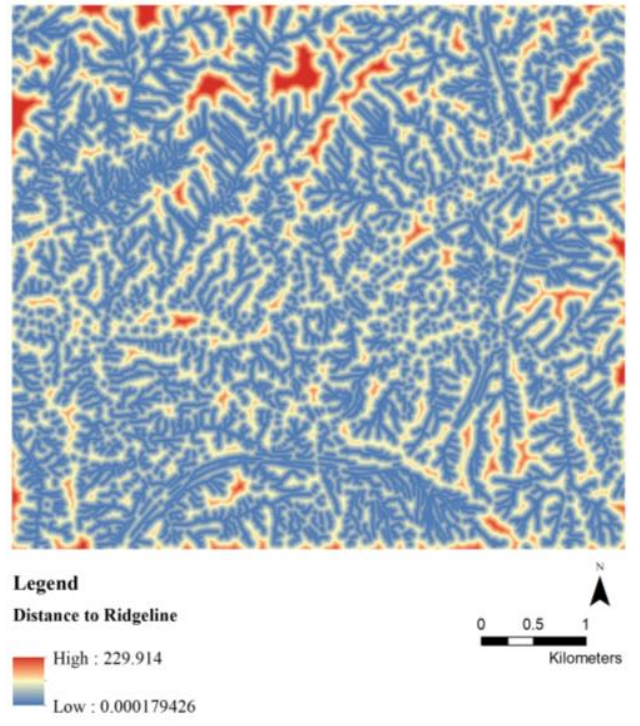

Figure 12. Distances to ridgelines.

\subsection{Land Use and Land Cover}

Understanding the purpose of land-uses on territory is essential on decision-making processes. LULC map with seven classes was produced from Sentinel-2 satellite images by supervised classification using the SNAP Tool of ESA. Random forest is chosen as supervised classification method. Training samples of main land-use categories are collected from the RGB bands of Sentinel-2 images. For improving classification accuracy, Gray-Level Co-Occurrence Matrix (GLCM) of the images were calculated for all directions. Classification was made by adding GLCM angular second moment (GLCM-ASM) parameter to the supervised classification (Figure 13).
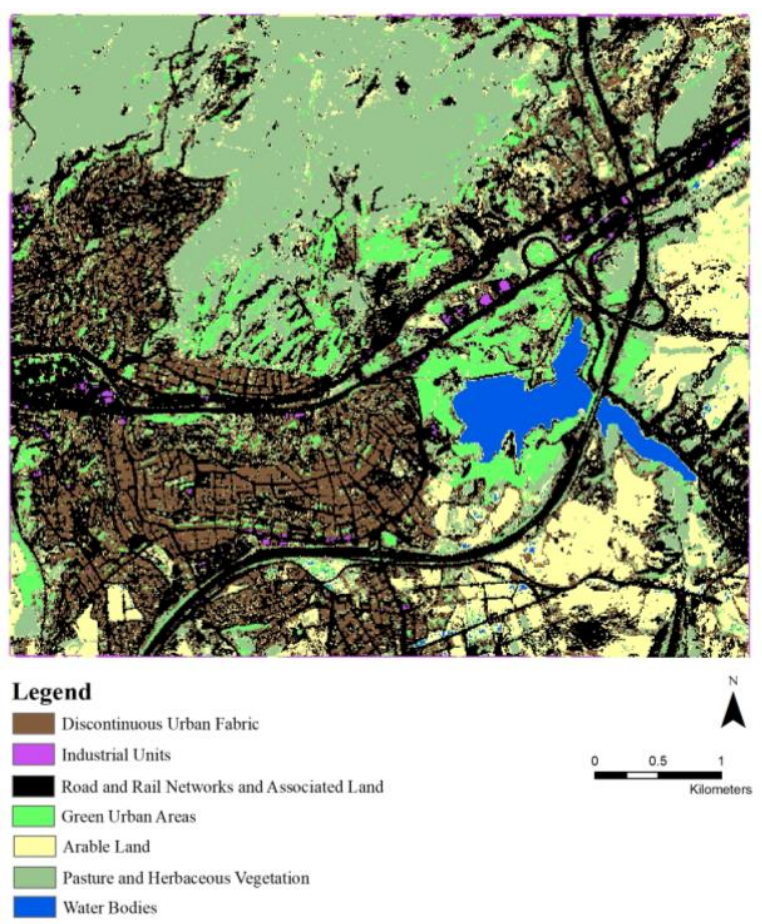

Figure 13. Land use and land cover map of the study area.

\subsection{Lithological Characteristics}

The lithology is one of the most important variable in the natural hazard analysis like land use and altitude (Pourghasemi and Kerle, 2016). Lithological descriptions are used for understanding the geological characteristics of the region. Lithological and structural differences generally lead to a change in robustness and permeability of rocks and soils (Ayalew and Yamagishi, 2005). Lithology map is provided by the General Directorate of Mineral Research and Exploration. There are five lithological features belonging to five ages in the area (Figure 14, Table 2).

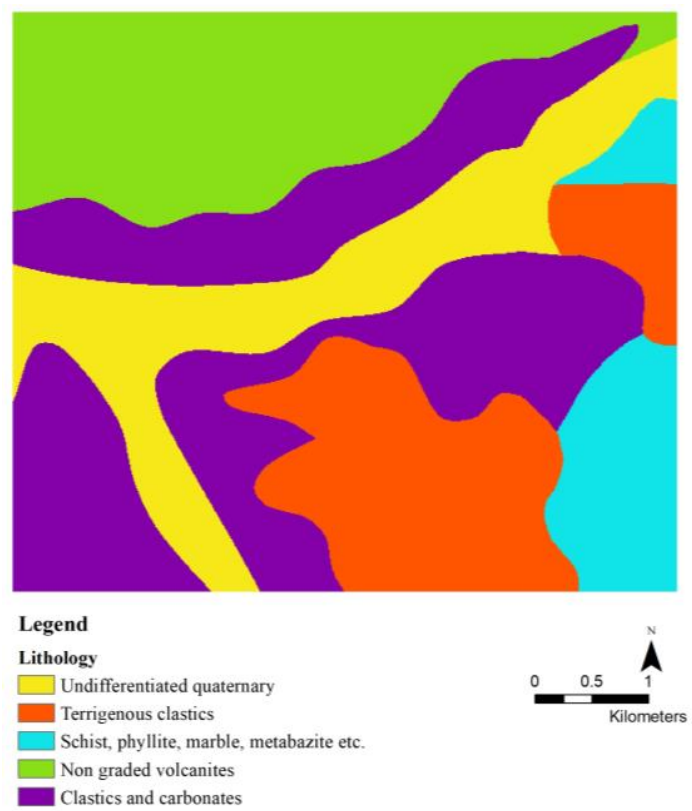

Figure 14. Lithology map of the study area

\begin{tabular}{|l|l|}
\hline Age & Description \\
\hline Pliocene & Terrigenous clastics \\
Quaternary & Undifferentiated quaternary \\
Permo - Triassic & Clastics and carbonates \\
Upper Paleozoic Tirassic & $\begin{array}{l}\text { Schist, phyllite, marble, } \\
\text { metabazite etc. }\end{array}$ \\
Lower-Middle Miocene & Non graded volcanites \\
\hline
\end{tabular}

Table 2. Lithological ages and descriptions in the study area

\subsection{Logistic Regression Method}

In this study, multivariate logistic regression is used for preparing landslide susceptibility map. Logistic regression is a statistical model used for landslide susceptibility maps to predict potential risk areas. Logistic regression method is preferred because it gives fast and accurate results for landslide risk detection (Budimir et al., 2014; Reichenbach et al., 2018). In this method, there are dependent and independent variables. Dependent variable is binary map which include occurrence or non-occurrence of landslides (Samia et al., 2017). Independent variables are topographic attributes, land use and lithology maps. Logistic regression model works with analyzing relationship between these dependent and independent variables and estimate potential risk areas. Logistic regression method is computed using the following equations:

$$
\begin{aligned}
& \mathrm{Y}_{\mathrm{i}}=\beta 0+\beta 1 \mathrm{X}_{\mathrm{i}} \\
& \mathrm{P}_{i}=\left(Y=1 / X_{i}\right)=1 / 1+\mathrm{e}-\left(\mathrm{Y}_{\mathrm{i}}\right)
\end{aligned}
$$


where $Y_{i}$ is the dependent variable, $x_{i}$ is the $i$-th covariate, $\beta_{0}$ is a constant and $\beta_{i}$ is the $\mathrm{i}$-th regression coefficient and $\mathrm{P}$ is the probability of the occurrence of landslides (Budimir et al., 2014). The existing landslide inventory and randomly selected non-landslide areas were used as training data in calculating the logistic regression parameters. The selected ratio between the landslide and non-slide pixels is 1:2.

\section{RESULTS AND DISCUSSION}

\subsection{Landslide Susceptibility Map}

Landslide susceptibility map is derived by using the eleven parameters. Figure 15 presents the landslide susceptibility map produced in this study. According to the map, the landslide risk in the study area are noticeable. The landslide susceptibility probability in the area range between $1-99 \%$. The susceptibility is higher in the west parts of the study. These areas are also subject for urban transformation projects.

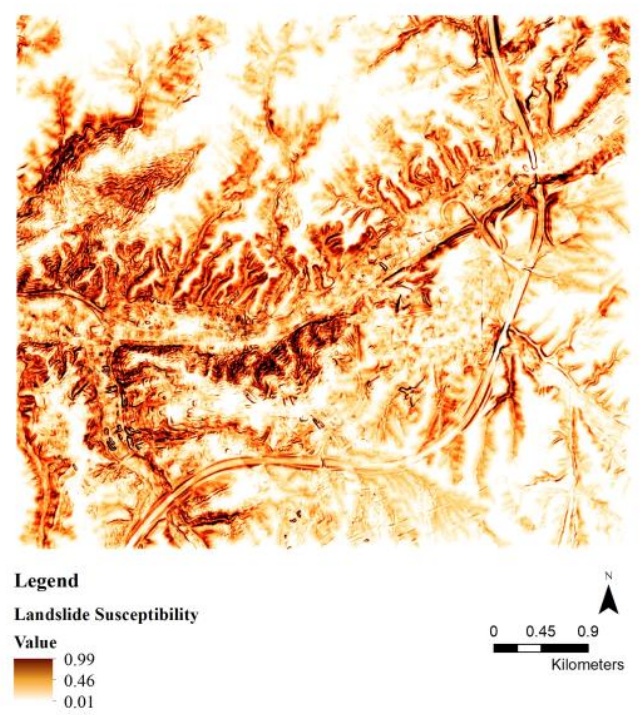

Figure 15. Landslide susceptibility map of the study area

The accuracy of the landslide susceptibility map is important for better understanding of the risks in the region. The accuracy depends in general on the quality of data, methodology, number of parameters used in the process and the type map generation (Ayalew and Yamagishi, 2005). The accuracy of the landslide susceptibility map can be interpreted from the ROC (Receiver Operating Characteristics) curves which is a measure for the capability of current model in classification (Perlich et al., 2003). Areas with and without landslide risks were $96 \%$ classified correctly (Figure 16). All parameters mentioned in the previous parts have effective role on the prediction of risks.

\subsection{Urban Transformation Plan}

The Mamak Urban Transformation Project (Figure 17) was implemented in a part of the study area that has a size of $7.389 .400 \mathrm{~m}^{2}$. The project was completed in 11 project stages under the cooperation of TOKI, which is a state organization for construction, Ankara Metropolitan Municipality and Mamak Municipality. The main goal of the project was to transform and modernize the slums, which is an unplanned settlement area with insufficient facilities and infrastructure
(Mamak Belediyesi, 2018). While the initial number of slums before the project started was 13.662, the number of slums destroyed at the time of this writing is 8.389. 30.000 dwellings are planned to be constructed in the project. As mentioned, Mamak has natural hazard potential and risks. The landside susceptibility map could be used to examine the vulnerability of the urban development and transformation plans within the study area (Figure 17).

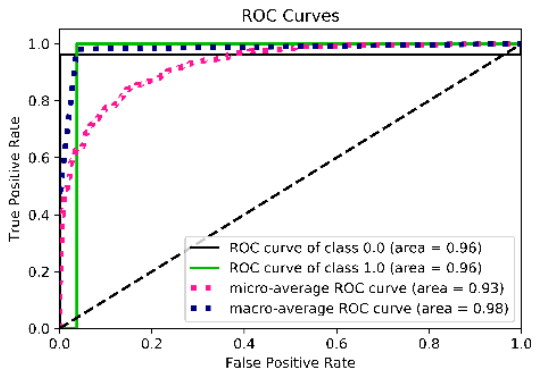

Figure 16. ROC curves of landslide susceptibility map
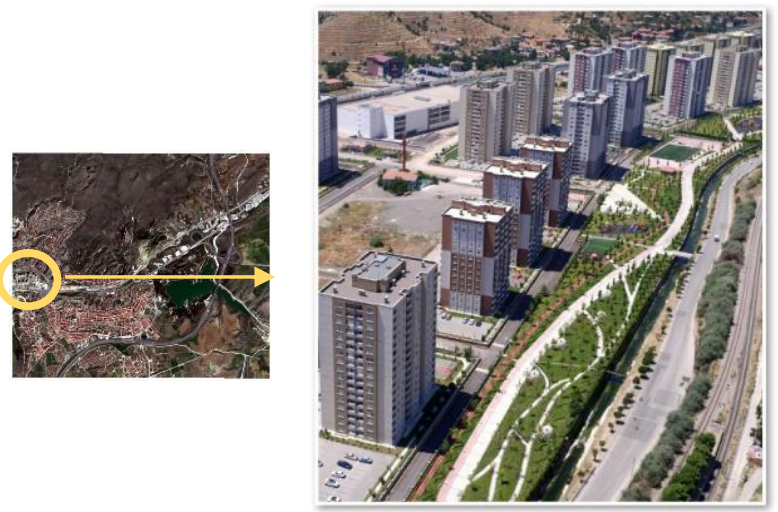

Figure 17. A part of urban transformation project within the study area.

\subsection{Discussion}

The DTM textured with both the Sentinel-2 image and the landslide susceptibility map of the study area were visualized in 3D with the QT Modeler (2019) software for analyzing the results (Figure 18 and Figure 19). Figures 20 and 21 show the existing and the planned urban transformation project areas. The existing project area (red circle in Figure 20) has very low landslide risk potential. It could be a sign for proper urban transformation project area although no attention is yet paid to other natural hazard potential. There are slum areas (blue circles in Figures 20 and 21) which are the potential urban transformation sites. Land use decisions of these areas should be prepared elaborately. It is more appropriate to evaluate these areas at high risk as urban green areas by establishing agreements with the property owners. There are also newly constructed buildings (green circle in Figure 21) in the west of Mamak region. The construction quality and the landslide resistance of these structures can be used as a criterion to measure the accuracy of the previous partial urban transformation in this area. 


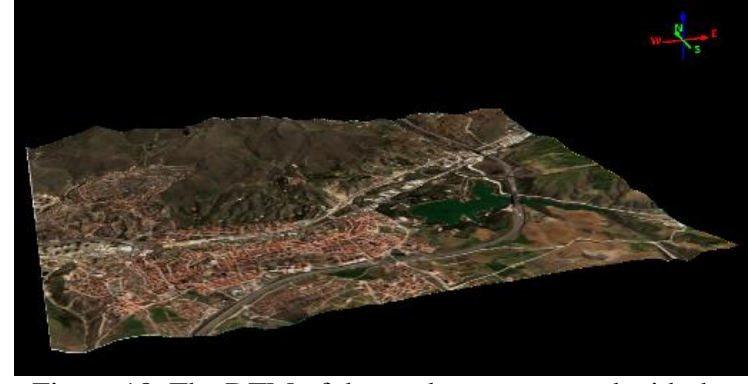

Figure 18. The DTM of the study area textured with the Sentinel-2 image.

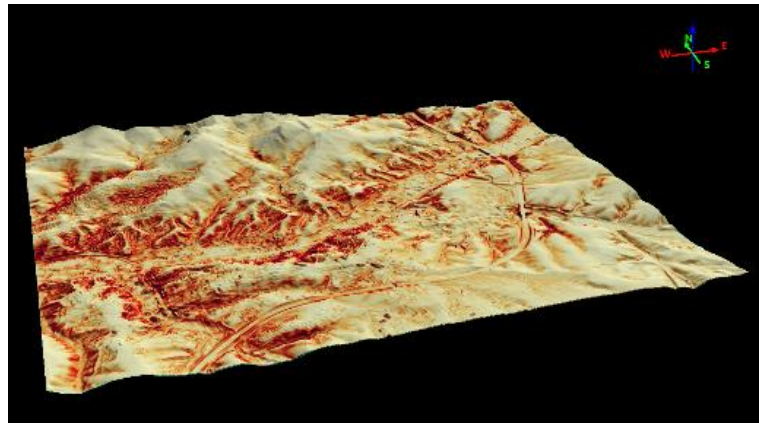

Figure 19. The DTM of the study area textured with the landslide susceptibility map (output of logistic regression).

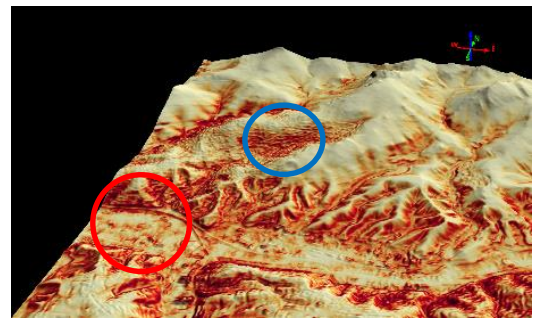

Figure 20. Important focal area for city planning in NorthWest Mamak.

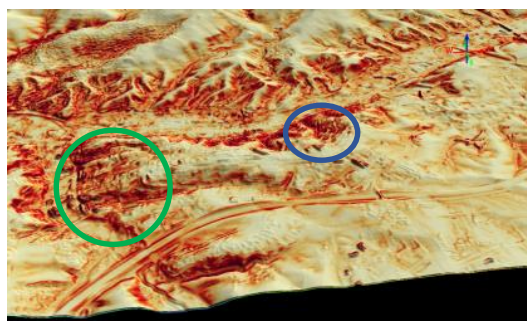

Figure 21. Important focal area for city planning in South Mamak.

\section{CONCLUSIONS}

In this study, the usability of Sentinel-2 images in landslide susceptibility mapping in urban development areas together with high-resolution DTM and the lithology data was investigated. The random forest classification method implemented in SNAP Tool is found successful for producing LULC classes from Sentinel-2 RGB images. Integrating the ASM parameter of GLCM helped to distinguish the industrial areas from the roads in the classification. The accuracy of the logistic regression method was found sufficient for the purposes of the study. Although the number of the training samples in manually delineated landslide areas was low, using the $1 / 2$ ratio for landslide/non-landslide samples worked efficiently. The produced landslide susceptibility map can be used as base for the urban development and transformation plans and further analysis is to be made for this purpose.

\section{ACKNOWLEDGEMENTS}

The authors sincerely thank to the General Directorate of Mapping and the General Directorate of Mineral Research and Explorations for provision of data; and Recep Can and Burhan Sözer from Hacettepe University for their continuous support.

\section{REFERENCES}

Akbaş, B., Akdeniz, N., Aksay, A., Altun, İ., Balcı, V., Bilginer, E., Bilgiç, T., Duru, M., Ercan, T., Gedik, İ., Günay, Y., Güven, İ.H., Hakyemez, H. Y., Konak, N., Papak, İ., Pehlivan, Ş., Sevin, M., Şenel, M., Tarhan, N.,Turhan, N., Türkecan, A., Ulu, Ü., Uğuz, M.F., Yurtsever, A. ve diğerleri, 2002. Türkiye Jeoloji Haritası. Maden Tetkik ve Arama Genel Müdürlüğü $\quad$ Yayını, $\quad$ Ankara, $\quad$ Türkiye. http://yerbilimleri.mta.gov.tr/ (20 July 2018).

Ayalew, L.,Yamagishi, H., 2005. The Application of GISBased Logistic Regression for Landslide Susceptibility Mapping in the Kakuda-Yahiko Mountains, Central Japan. Geomorphology, 65, 15-31.

Budimir, M., Atkinson, P., Lewis, H., 2014. Seismically induced landslide hazard and exposure modelling in Southern California based on the 1994 Northridge, California earthquake event. Landslides, 12, 1-16. doi.org/10.1007/s10346-014-0531-8.

Chen, L., Guo, Z., Yin, K., Shrestha, D. P., and Jin, S., 2019. The influence of land use and land cover change on landslide susceptibility: A case study in Zhushan Town, Xuanen County (Hubei, China). Natural Hazards and Earth System Sciences Discussions. doi.org/10.5194/nhess-2019-203.

ESA, 2019.

https://sentinel.esa.int/web/sentinel/missions/sentinel-2 January 2019)

Esri, 2019. https://www.esri.com/ (20 July 2018)

Gorum, T., Gonencgil, B., Gokceoglu, C., Nefeslioglu, H.A., 2008. Implementation of reconstructed geomorphologic units in landslide susceptibility mapping: The Melen Gorge (NW Turkey). Natural Hazards, 46 (3), 323-351.

Kakembo, V., Xanga, W. W., \& Rowntree, K., 2009. Topographic thresholds in gully development on the hillslopes of communal areas in Ngqushwa Local Municipality, Eastern Cape, South Africa. Geomorphology, 110(3-4), 188-194. doi.org/10.1016/j.geomorph.2009.04.006

Mamak Belediyesi, 2018. Mamak Belediyesi 2018 Yılı İdare Faaliyet Raporu. Ankara.

Moore, I. D., Grayson, R. B., Ladson, A. R., 1991. Digital terrain modelling: A review of hydrological, geomorphological, and biological applications. Hydrological Processes, 5(1), 3-30. 
Nefeslioglu, H.A., Gokceoglu, C., Sonmez, H., 2008. An assessment on the use of logistic regression and artificial neural networks with different sampling strategies for the preparation of landslide susceptibility maps. Engineering Geology, 97 (3/4), 171-191.

Mulero, D. L., Nja, O., Fernandez, C. L., 2018. Landslide Risk Management in the Urban Development of Sandnes (Norway). The International Archives of the Photogrammetry, Remote Sensing and Spatial Information Sciencess, Volume XLII3/W4

Perlich, C., Provost, F., Simonoff, J., 2003. Tree Induction vs. Logistic Regression: A Learning-Curve Analysis. Journal of Machine Learning Research, 4. 211-255. doi.org/10.1162/153244304322972694.

Pham, B.T., Shirzadi, A., Tien Bui, D., Prakash, I., Dholakia, M., 2018. A hybrid machine learning ensemble approach based on a radial basis function neural network and rotation forest for landslide susceptibility modeling: a case study in the Himalayan area, India. International Journal of Sediment Research, 33, 157-170.

Poursanidis, D., Chrysoulakis, N., 2017. Remote Sensing, Natural Hazards and the Contribution of ESA Sentinels Missions. Remote Sensing Applications: Society and Environment, 6, 25-38.

QT Modeler, 2019. http://appliedimagery.com/ (20 July 2019)

Reichenbach, P., Rossi, M., Malamud, B. D., Mihir, M., \& Guzzetti, F., 2018. A review of statistically-based landslide susceptibility models. Earth-Science Reviews, 180, 60-91. doi.org/10.1016/j.earscirev.2018.03.001

SAGA GIS, 2019. www.saga-gis.org (20 July 2019)

Samia, J., Temme, A., Bregt, A., Wallinga, J., Guzzetti, F., Ardizzone, F., Rossi, M., 2017. Characterization and quantification of path dependency in landslide susceptibility. Geomorphology, 292, 16-24. doi.org/10.1016/j.geomorph.2017.04.039

Sentinel-2 coverage map, 2019.

https://sentinel.esa.int/web/sentinel/user-guides/sentinel-2msi/revisit-coverage (27 January 2019)

Zakerinejad, R., Maerker, M., 2015. An integrated assessment of soil erosion dynamics with special emphasis on gully erosion in the Mazayjan basin, southwestern Iran. Natural Hazards, 79(S1), 25-50. doi.org/10.1007/s11069-015-1700-3

Wilson, J. P., Gallant, J. C., 2000. Digital terrain analysis. Terrain analysis: Principles and applications, 6(12), 1-27. 